\title{
Productivity Properties of Protein-lipid Film (Yuba) Prepared from Different Soybean Cultivars in China
}

\author{
Qun SHEN ${ }^{1}$, Xiujin ZHANG ${ }^{1}$, Zhi HAN ${ }^{1,2}$, Zaigui LI ${ }^{1 *}$ and Masayoshi SAITO ${ }^{3}$ \\ ${ }^{1}$ College of Food Science and Nutritional Engineering, China Agricultural University \\ (Beijing 100083, P. R. China) \\ ${ }^{3}$ Research Planning and Coordination Division, Japan International Research Center for Agricultural \\ Sciences (JIRCAS) (Tsukuba, Ibaraki 305-8686, Japan)
}

\begin{abstract}
Seven Chinese soybean cultivars were used to prepare protein-lipid film (yuba). Protein-lipid film was prepared from soymilk with ohmic heating. It was shown that both protein and lipid concentrations of soymilk affected productivity properties, but protein-lipid ratio was a more important factor for protein-lipid film formation. When the concentration of lipid in soymilk and protein-lipid ratio were $15.0-18.0 \%$ and $2.70-3.00$ respectively, the yield and film formation rate were high, and the electricity consumption was relatively low. The results were useful for choice of a suitable cultivar of soybean for protein-lipid film production.

Discipline: Food

Additional key words: ohmic heating, soymilk, traditional food
\end{abstract}

\section{Introduction}

Soy protein-lipid film, designated as yuba or soymilk skin, is formed during the heating of soymilk ${ }^{10}$. Protein-lipid film is a kind of traditional soybean food which is delicious and of high nutritional value ${ }^{8}$. The protein digestion rate of protein-lipid film is almost $100 \%{ }^{6}$. Protein-lipid film is a very popular food material in China; the yield per year was over 200,000 tons at the end of 20th century. Protein-lipid film is called yuba and is one of the popular traditional soybean foods in Japan as well.

The formation mechanism of protein-lipid film is entirely different from that of tofu which is another traditional soybean food. Tofu is a kind of gel formed by the addition of solidification reagents such as $\mathrm{CaCO}_{3}$ and is mainly composed of protein, lipid and water. On the other hand, protein-lipid film is formed as a result of endothermic polymerization of heat denatured proteins or lipoprotein monomers at the liquid surface promoted by surface dehydration. Heating of soymilk leads to a change in the three-dimensional structure of proteins and results in exposing sulphydryl groups and hydrophobic side chains ${ }^{11}$. In tofu processing, proteins create a framework, while lipid and water are buried in networks. Therefore, high protein concentration is beneficial for tofu gel formation. During the film-formation of yuba, lipid acts as a surfactant which moves to the air/water interface and interacts with proteins by hydrophobic interactions. Furthermore, some of the lipids can be buried in a protein network structure during the protein-lipid film formation ${ }^{7}$. It was also reported that protein created a framework in the protein-lipid film structure, while lipids were dispersed in it as droplets ${ }^{1,13}$.

Since protein and lipid count for about $80 \%$ of the film based on a dry basis ${ }^{3,10}$, it is assumed that the effects of soybean cultivars on the productivity of protein-lipid film was mainly due to the concentrations of protein and lipid in the soymilk. Therefore, suitability of soybean cultivars for protein-lipid film production would be different from that for tofu making.

There are some reports on the effects of protein and lipid contents on the productivity of protein-lipid film. Wu $\&$ Bates ${ }^{10}$ reported that the optimal protein concentration of soymilk ranged from $1.5 \%$ to $3.0 \%$ (wet basis) for the film yield in the soybean protein isolate (SPI) system and $2.4 \%$ for film formation rate. Wu \& Bates ${ }^{11}$ pointed out that lipid emulsification in soymilk was beneficial for film formation. $\mathrm{Wu} \&$ Bates ${ }^{12}$ revealed that poor productivity

\footnotetext{
Present address:

${ }^{2}$ China Quality Certification Center (Beijing 100070, P. R. China)

*Corresponding author: e-mail lizg@cau.edu.cn

Received 8 April 2008; accepted 7 July 2008.
} 
of protein-lipid film occurred in systems with a low protein-lipid ratio under 1.00 .

The suitability of soybean cultivars for protein-lipid film production is still not clear. Protein-lipid film producers often think that the protein content of soybean is "the higher, the better" from the experience of tofu making. Thereby, they tend to select the soybeans with high protein content. However, since the formation mechanism of protein-lipid film is different from that of tofu, there may be some other factors than protein content which is dominant in protein-lipid film productivity.

In this study, we selected seven Chinese soybean cultivars which were widely used for the production of protein-lipid film to investigate the effects of protein and lipid concentrations and protein-lipid ratio in soymilk on the productivity properties. In addition, the protein and lipid concentrations of soymilk were adjusted by adding SPI and soybean oil, in order to investigate in a wider range of protein and lipid concentrations than that of the original soymilk. Three indexes, such as protein input efficiency (PIE), lipid input efficiency (LIE) and electricity consumption were investigated to verify the productivity as well.

\section{Materials and methods}

\section{Materials}

Seven Chinese soybean cultivars were used; those were Dalubai (DLB), Heisheng101 (HS101), Jiyu54 (JY54), Jiyu64 (JY64), Shifeng7 (SF7), Suinong14 (SN14), and Kenxin3 (KX3).

SPI was obtained from Jilin Fuji Protein Co., Ltd. (China). Soybean oil was purchased at a local supermarket. Emulsifier (calcium stearoyl lactylate, CSL) was purchased from Danisco Co., Ltd. (China).

\section{Soymilk preparation}

After impurity removal, $150 \mathrm{~g}$ of soybean was washed 3-4 times with distilled water and soaked in distilled water (water-soybean weight ratio of $3.5: 1$ ) for $12 \mathrm{~h}$ at room temperature (about $25^{\circ} \mathrm{C}$ ). Then, soybean were drained and milled with distilled water in a FDM-Z100 soymilk machine (Guangzhou Henlian Food Machine Co., Ltd., China). The soluble solids content (SSC) of the resulting soymilk was adjusted to $6.0 \%{ }^{6}$, which was determined by a refractometer (RHD 25, Fuzhou Link Optical Instrument Co., Ltd., China). The soymilk was filtered through 80 mesh gauze, $100 \mathrm{~g}$ of soymilk was freeze dried for the analysis of protein and lipid concentrations and the rest was preserved at $10^{\circ} \mathrm{C}$ for protein-lipid film preparation.

\section{Adjustment of protein and lipid concentrations of soymilk}

Protein and lipid concentrations of soymilk prepared from KX3 were adjusted using SPI solution and soybean oil emulsion.

SPI solutions were prepared by dissolving different quantities of SPI in $900 \mathrm{~g}$ distilled water and these were kept for $12 \mathrm{~h}$ at room temperature.

Soybean oil emulsions were prepared as follows; different quantities of soybean oil and emulsifier (CSL, $1 / 1,000 \mathrm{w} / \mathrm{w}$ of soybean oil) were put into water, and the mixture was stirred with a magnetic stirrer until the oil became minute globules suspended in the water. Then the suspension was homogenized using a high-pressure homogenizer (GBY60-65, Shanghai Donghua High-pressure Homogenizer Factory, Shanghai, China) at $25 \mathrm{Mpa}$ pressure to form a stable emulsion.

The SPI solution and the soybean oil emulsion were added to soaked soybean. The mixture was milled and SSC of the resulting soymilk was adjusted to $6.0 \%$.

\section{Protein-lipid film preparation}

Protein-lipid film was prepared by an ohmic heating machine which was developed by our laboratory. Soymilk $(500 \mathrm{~mL})$ was heated and kept at higher than $95^{\circ} \mathrm{C}$ for $3-4$ min in a heating trough $(13 \times 13 \times 10 \mathrm{~cm})$, then shifted to the film forming trough $(14 \times 25 \times 5 \mathrm{~cm})$, the heating temperature was set at $85^{\circ} \mathrm{C}$. Protein-lipid film was picked up from the surface every $10 \mathrm{~min}$ and drained for a few seconds. Electricity consumption was measured during the heating. After airing for $5 \mathrm{~min}$ at room temperature, protein-lipid film was weighed. The residual soymilk after protein-lipid film formation was freeze dried for subsequent chemical analyses. Experiments were carried out in duplicate.

\section{Proximate analysis}

Protein and lipid were determined by the Kjeldahl method and Soxhlet extraction method according to the national standard of the People's Republic of China (GB/ $\mathrm{T} 5511-1985)^{5}$ using a conversion factor of 5.7 and GB/ T5009.6-19854, respectively. Moisture contents were measured according to AACC method 44-16 (AACC, $1983)^{2}$. Samples were heated at $130^{\circ} \mathrm{C}$ for $40 \mathrm{~min}$ and then the moisture contents were calculated.

\section{Calculation methods}

\section{(1) Yield and film formation rate}

Yield referred to the protein-lipid film yield of every $100 \mathrm{~mL}$ soymilk, while film formation rate referred to the protein-lipid film yield every $10 \mathrm{~min}$. They were calculated as follows: 


$$
\begin{aligned}
& Y=\frac{M \times 100}{G} \\
& V=\frac{M \times 10}{T}
\end{aligned}
$$

where $\mathrm{Y}$ and $\mathrm{V}$ were the yield $(\mathrm{g} / 100 \mathrm{ml})$ and film formation rate $(\mathrm{g} / 10 \mathrm{~min})$ respectively, $\mathrm{M}$ was the total proteinlipid film output (g), G was the volume of soymilk for film formation ( $\mathrm{ml}$ ), and $\mathrm{T}$ is the total time for film formation (min).

\section{(2) Protein input efficiency (PIE) and lipid input efficiency (LIE)}

PIE/LIE referred to the percentage of the protein/lipid of the protein-lipid film accounting for the total protein/lipid of $100 \mathrm{~mL}$ soymilk. They were calculated as follows:

$$
\begin{aligned}
& P I E=\frac{P^{\prime}-P}{P^{\prime}} \times 100 \\
& L I E=\frac{L^{\prime}-L}{L^{\prime}} \times 100
\end{aligned}
$$

where $\mathrm{P}^{\prime}$ and $\mathrm{P}$ were the total protein and the residual protein $(\mathrm{g})$ of $100 \mathrm{~mL}$ soymilk, respectively, and $\mathrm{L}^{\prime}$ and $\mathrm{L}$ the total lipid and the residual lipid (g) of $100 \mathrm{~mL}$ soymilk, respectively.

(3) Electricity consumption per kilogram wet proteinlipid film

Electricity consumption during film formation was measured by DDS237 Single-phase Electronic Meter (Shanghai Huali Electric Meter Works, China) as follows:

$$
E=\frac{E^{*}}{M} \times 1000
$$

where $\mathrm{E}$ was the electricity consumption per kilogram wet protein-lipid film $(\mathrm{kw} \cdot \mathrm{h} / \mathrm{kg}), \mathrm{E}^{*}$ was the total electricity consumption during the film formation in each trial $(\mathrm{kw} \cdot \mathrm{h})$ and $\mathrm{M}$ was the total output of protein-lipid film $(\mathrm{kg})$.

\section{Results and discussion}

\section{Effects of soybean cultivars on protein-lipid film production}

Main components and protein-lipid film production properties of 7 Chinese soybean cultivars are shown in Table 1. The water uptake of soybean during the soaking was about $120.0 \%$ and water added during the milling process was 9-10 times of the weight of soybean to adjust SSC to $6.0 \%$. Range of protein content of 7 cultivars was $33.8 \%$ to $45.4 \%$ and that of lipid content was $17.8 \%$ to $22.9 \%$. The protein-lipid ratios of soybean are also given in Table 1. Protein-lipid ratio was in a range of 1.62 to 2.48. Protein-lipid ratio of soymilk was higher than those of soybean, in a range of 2.16 to 3.18 . In the results of protein-lipid film yield, HS101 showed the best and SF7 showed the worst behavior for protein-lipid film production. KX3 showed poor behavior for the production as well.

The effects of protein and lipid concentration of soymilk on protein-lipid film production of various soybean cultivars are shown in Fig. 1. As shown in Fig. 1 (a), protein concentration of soymilk had some effects on protein-lipid film yield and film formation rate. When the protein concentration of soymilk was about $45 \%$, the yield was the highest. However, there was no obvious correlation between them. It was shown that some factors

\begin{tabular}{|c|c|c|c|c|c|c|c|c|}
\hline $\begin{array}{l}\text { Soybean } \\
\text { cultivars }\end{array}$ & $\begin{array}{c}\text { Moisture } \\
\text { (\%) }\end{array}$ & $\begin{array}{l}\text { Protein } \\
\left(\% \mathrm{db}^{*}\right)\end{array}$ & $\begin{array}{l}\text { Lipid } \\
(\% \mathrm{db})\end{array}$ & $\begin{array}{l}\text { Protein-lipid } \\
\text { ratio of soybean }\end{array}$ & $\begin{array}{l}\text { Protein of } \\
\text { soymilk } \\
(\% \mathrm{db})\end{array}$ & $\begin{array}{l}\text { Lipid of } \\
\text { soymilk } \\
(\% \mathrm{db})\end{array}$ & $\begin{array}{l}\text { Protein-lipid } \\
\text { film yield } \\
(\mathrm{g} / 100 \mathrm{~mL})\end{array}$ & $\begin{array}{l}\text { Protein-lipid film } \\
\text { formation rate } \\
\qquad(\mathrm{g} / 10 \mathrm{~min})\end{array}$ \\
\hline JY64 & 9.1 & 37.2 & 22.9 & 1.62 & 45.8 & 19.6 & 7.58 & 3.79 \\
\hline SF7 & 9.5 & 33.8 & 17.8 & 1.90 & 44.1 & 20.4 & 7.25 & 3.63 \\
\hline JY54 & 9.5 & 40.8 & 21.3 & 1.92 & 50.5 & 17.4 & 8.88 & 4.44 \\
\hline SN14 & 8.7 & 41.7 & 20.5 & 2.03 & 45.5 & 18.0 & 8.90 & 4.45 \\
\hline DLB & 9.7 & 38.1 & 18.1 & 2.10 & 47.4 & 14.9 & 7.91 & 3.95 \\
\hline HS101 & 9.5 & 45.4 & 18.3 & 2.48 & 45.8 & 15.9 & 9.67 & 4.84 \\
\hline KX3 & 9.3 & 38.8 & 18.5 & 2.10 & 38.6 & 9.2 & 7.40 & 3.53 \\
\hline
\end{tabular}
other than protein concentration of soymilk were also important for the yield of protein-lipid film.

The effects of lipid concentration were investigated.

Table 1. Main components and protein-lipid film production properties of various soybean cultivars

JY64: Jiyu 64, SF7: Shifeng 7, JY54: Jiyu 54, SN14: Suinong 14, DLB: Dalubai, HS101: Heisheng 101, KX3: Kenxin 3. All are Chinese soybean cultivars.

*: dry basis 


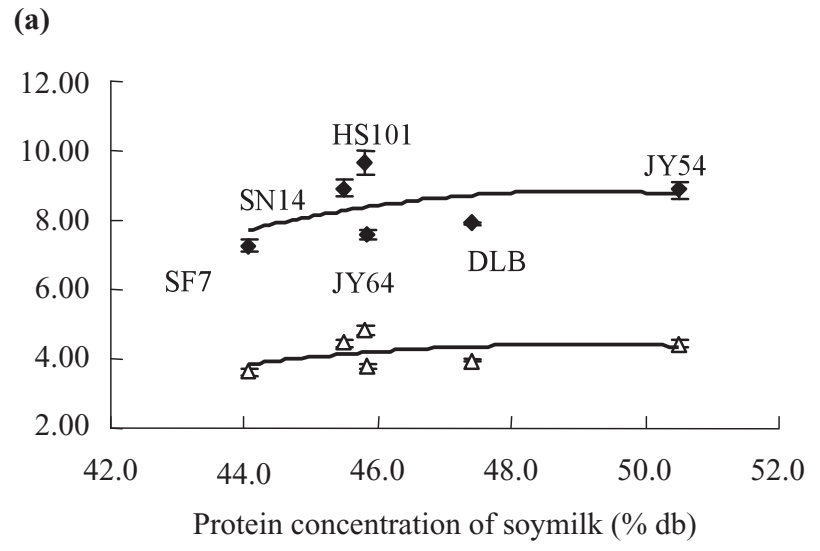

(b)

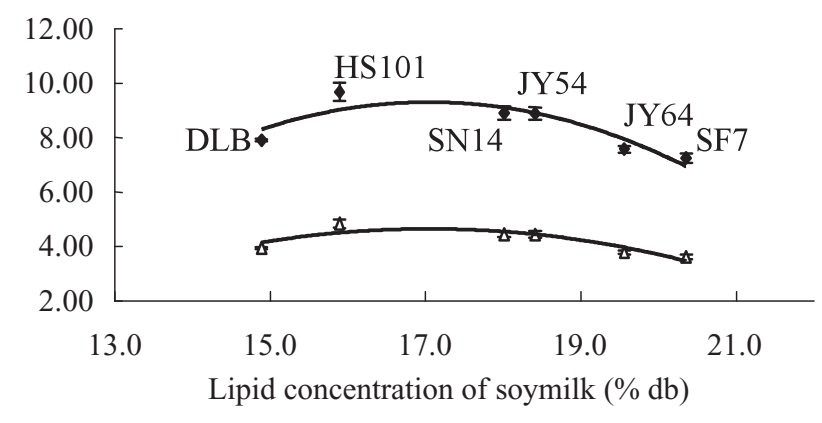

Fig. 1. Effects of protein and lipid concentration of soymilk prepared from various soybean cultivars on proteinlipid film production

DLB: Dalubai, HS101: Heisheng 101, JY54: Jiyu 54, JY64: Jiyu 64, SF7: Shifeng 7, SN14: Suinong

14. All are Chinese soybean cultivars.

(a): Protein concentration, (b): Lipid concentration.

: Yield $(\mathrm{g} / 100 \mathrm{~mL}), \triangle$ : Film formation rate $(\mathrm{g} / 10$ $\min )$.

Vertical bars indicate standard errors.

Fig. 1 (b) indicated that there was a notable relationship between lipid concentration and both protein-lipid film yield and film formation rate. As the lipid concentration increased, both the protein-lipid film yield and film formation rate increased at first (the optimum lipid concentration was about 16-18\%) and then decreased. It was reported that a lower lipid concentration was necessary for better film quality ${ }^{12}$, but our results indicated that appropriate lipid concentration is essential for film formation, which is in accord with the conclusion of Wu \& Bates ${ }^{11}$.

The effects of protein-lipid ratio of soymilk of various soybean cultivars were further studied. As shown in Fig. 2 , as protein-lipid ratio increased the protein-lipid film yield and formation rate increased at first and then decreased, and the optimum condition was obtained when the ratio was between 2.70 and 2.90 .

During the protein-lipid film formation, lipids are thought to be combined with proteins by non-covalent

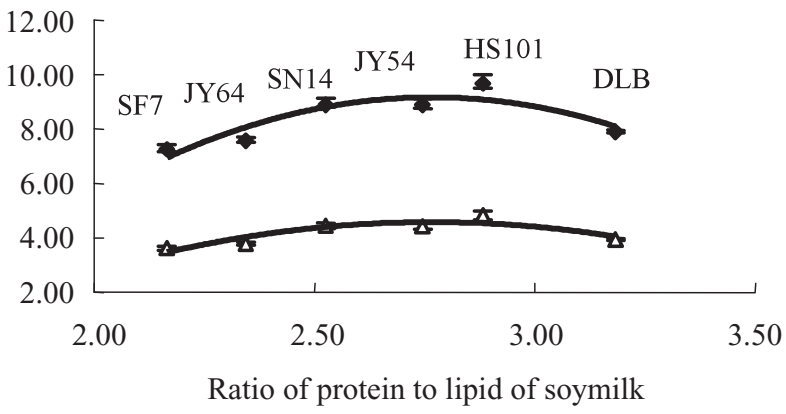

Fig. 2. Effects of ratio of protein to lipid of soymilk prepared from various soybean cultivars on protein-lipid film production

DLB, HS101, JY54, JY64, SF7, SN14: Same as in Fig. 1.

$\diamond$ : Yield $(\mathrm{g} / 100 \mathrm{~mL}), \triangle$ : Film formation rate $(\mathrm{g} / 10$ $\min$ ).

Vertical bars indicate standard errors.

bonds. On the other hand, large amounts of lipids are trapped in a network structure formed during protein denaturalization ${ }^{9}$. Interaction between proteins and lipids also had great effects on the protein-lipid film production. If lipid concentration was not enough, the protein network structure would not be filled well. In contrast, there would not be enough protein structure for excessive lipid ${ }^{7}$. Therefore, suitable protein-lipid ratio may be an important factor for the film yield and formation rate.

It was obvious that the protein-lipid ratio of the soybean cultivar and that of soymilk prepared from the cultivar were different just as shown in Table 1. The proteinlipid ratio of soymilk is considered to be a character of the cultivars themselves, and we can conclude that a soybean cultivar which has high protein content and high proteinlipid ratio at the same time would be suitable for the production of protein-lipid film.

\section{Effects of protein and lipid concentrations of soymilk on protein-lipid film production}

(1) Effects of protein and lipid concentrations of soymilk adjusted by SPI and soybean oil

To affirm the effects of protein-lipid ratio in a larger range on productivity, the components of soymilk (prepared from cultivar Kenxin 3, KX3) were adjusted by adding SPI or soybean oil. Protein content and lipid content of SPI was $79.2 \% \mathrm{db}$ and $0.9 \% \mathrm{db}$, respectively.

As shown in Fig. 3, the optimum lipid concentration for yield and film formation rate was about $15.5 \%$. Even when the protein concentrations were almost at the same level, the protein-lipid film yield and film formation rate obtained were different if the lipid concentration was different. For example, when protein concentrations of 
two samples were $44.0 \%$ and $44.2 \%$ while lipid concentrations were $13.1 \%$ and $9.6 \%$ respectively, the former had higher film yield and formation rate. The same thing was observed in lipid concentrations. When lipid concentrations of two samples were $10.6 \%$ and $11.1 \%$ while protein concentrations were $42.7 \%$ and $60.6 \%$ respectively, the latter had higher film yield and formation rate. Thereby, both protein and lipid concentrations affected the production of protein-lipid film.

\section{(2) Effects of protein-lipid ratio of soymilk adjusted by}

\section{SPI and soybean oil}

The effect of ratio of protein to lipid of soymilk on the protein-lipid film production was further studied. As shown in Fig. 4, protein-lipid ratio had a regular effect. As protein-lipid ratio increased, the protein-lipid film yield and film formation rate increased until the ratio was 2.83 and then decreased.

Protein-lipid ratio significantly affected both proteinlipid film yield and film formation rate, and optimum condition was obtained when protein-lipid ratio ranged from 2.80

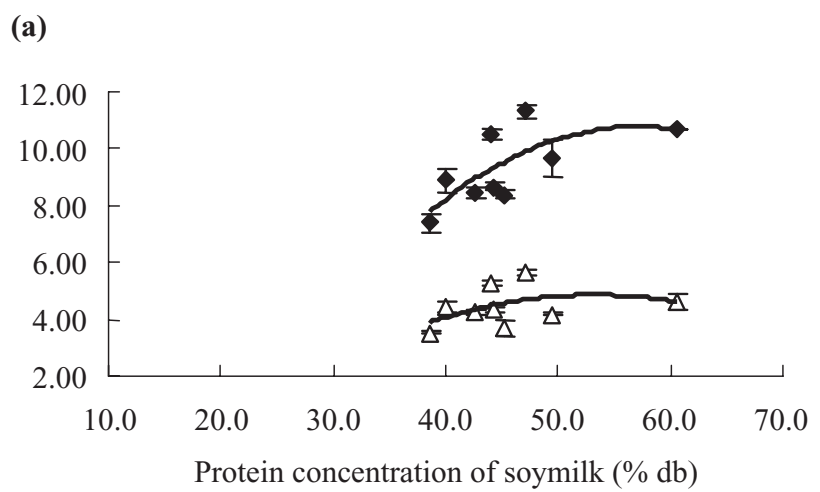

(b)

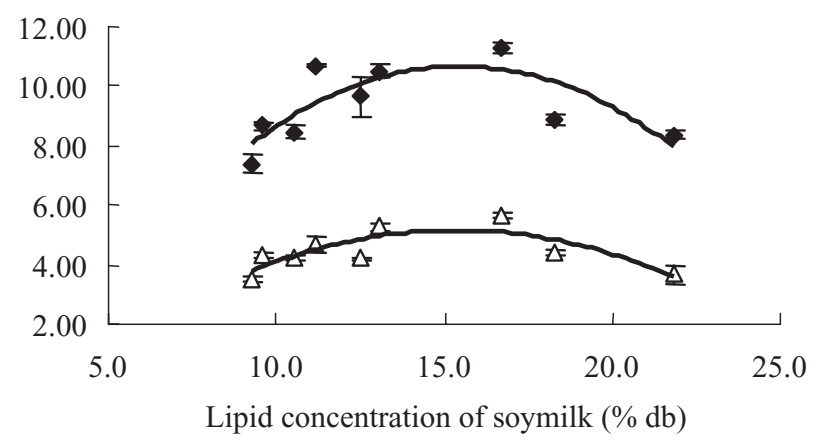

Fig. 3. Effects of protein and lipid concentrations of soymilk adjusted by SPI and soybean oil on protein-lipid film production

(a): Protein concentration, (b): Lipid concentration.

$\diamond$ : Yield $(\mathrm{g} / 100 \mathrm{~mL}), \triangle$ : Film formation rate $(\mathrm{g} / 10$ $\min$ ).

Vertical bars indicate standard errors. to 3.00. We concluded that protein-lipid ratio was an important factor affecting the production of protein-lipid film.

(3) Effects of protein concentration of soymilk on PIE and lipid concentration on LIE

Effects of protein concentration of soymilk adjusted by SPI on PIE are shown in Fig. 5. It indicated that PIE ranged between $70 \%$ and $80 \%$ regardless of the protein concentration of soymilk. It was shown that the protein concentration of soymilk had little influence on PIE.

Effects of lipid concentration of soymilk adjusted by soybean oil on LIE are shown in Fig. 6. The lipid concentration of soymilk had a significant effect on LIE as shown in Fig. 6. As the lipid concentration increased, LIE increased until about $94 \%$ and then decreased. However, the difference was not statistically significant. It can be said that in a range of $0.65-1.08 \%$ of lipid concentrations of soymilk, LIE would be higher than $90 \%$.

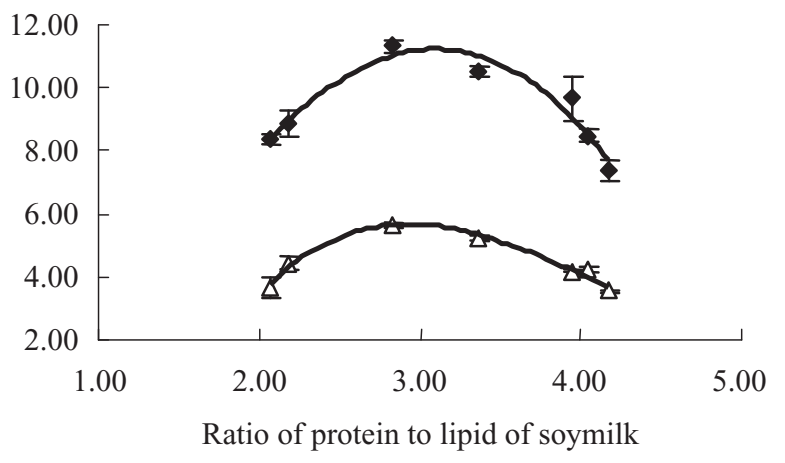

Fig. 4. Effects of protein-lipid ratio of soymilk adjusted by SPI and soybean oil on the protein-lipid film production

$\diamond:$ Yield $(\mathrm{g} / 100 \mathrm{~mL}), \triangle$ : Film formation rate $(\mathrm{g} / 10$ $\min )$.

Vertical bars indicate standard errors.

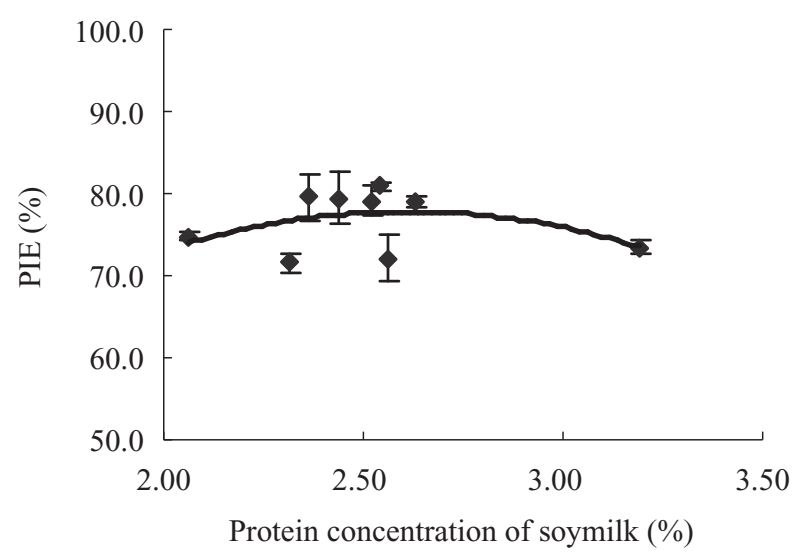

Fig. 5. Effects of protein concentration of soymilk adjusted by SPI on PIE

Vertical bars indicate standard errors. 


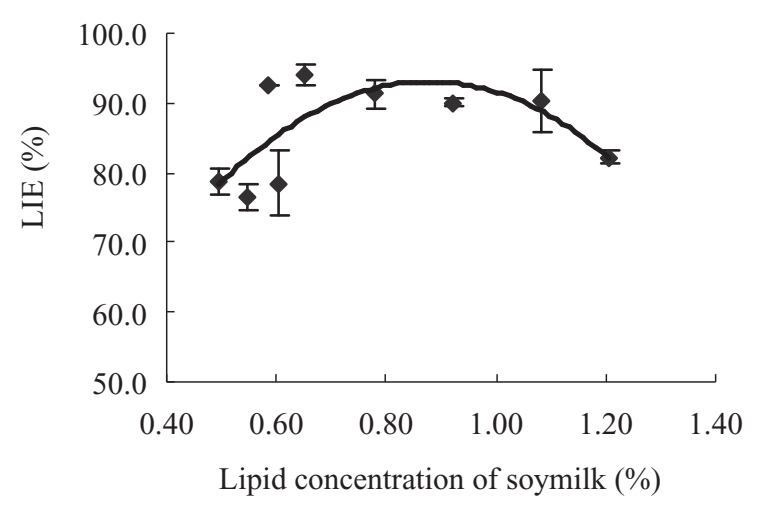

Fig. 6. Effects of lipid concentration of soymilk adjusted by soybean oil on LIE

Vertical bars indicate standard errors.

Both Fig. 5 and Fig. 6 show that a suitable concentration of protein or lipid can improve the PIE or LIE. That is to say, suitable components of soymilk improved not only the yield and quality, but also the use efficiency of soymilk.

(4) Effects of protein and lipid concentration of soymilk on electricity consumption

The effects of protein and lipid concentrations of soymilk on electricity consumption are shown in Fig. 7. As the protein concentration increased, electricity consumption decreased about $39 \%$ at first and then it held the line. With the increase of lipid concentration, the electricity consumption decreased about $41 \%$ at first and increased when the lipid concentration was higher than $0.9 \%$.

As the lipid concentration increases, lipid can be trapped in the protein network easily, thereby, the power consumption decreased. However, when the lipid concentration was at a relatively high level, electricity consumption increased, that may be because of the low electric conductivity of lipid. Electricity consumption was relatively lower when the protein concentration of the soymilk was over $3.0 \%$ or the lipid concentration was around $0.8 \%$.

The effects of protein-lipid ratio of soymilk on electricity consumption are shown in Fig. 8. As protein-lipid ratio increased, electricity consumption decreased about $25 \%$ at first, and then increased. Electricity consumption was relatively lower when protein-lipid ratio was around 3.5.

Energy shared about $30 \%$ or more of the cost of protein-lipid film production. The efficiency of energy may be affected by equipment, ventilation and so on, but it was clear that electricity consumption could be improved by using soybean cultivars which have suitable protein and lipid concentrations. Those findings are thought to be beneficial for the protein-lipid film industry. (a)

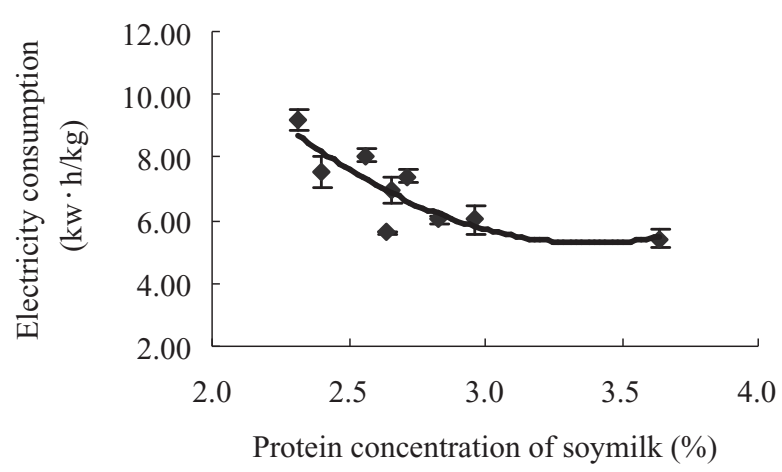

(b)

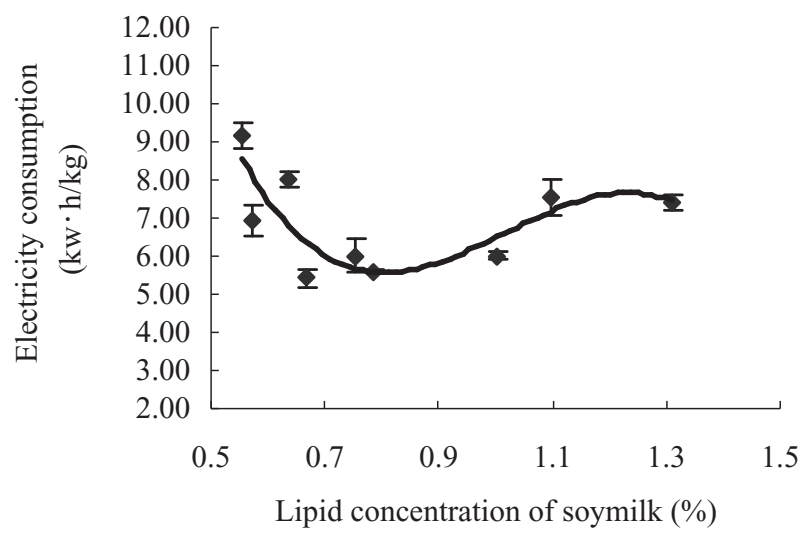

Fig. 7. Effects of protein and lipid concentrations of soymilk adjusted by SPI and soybean oil on electricity consumption

(a): Protein concentration, (b): Lipid concentration. Vertical bars indicate standard errors.

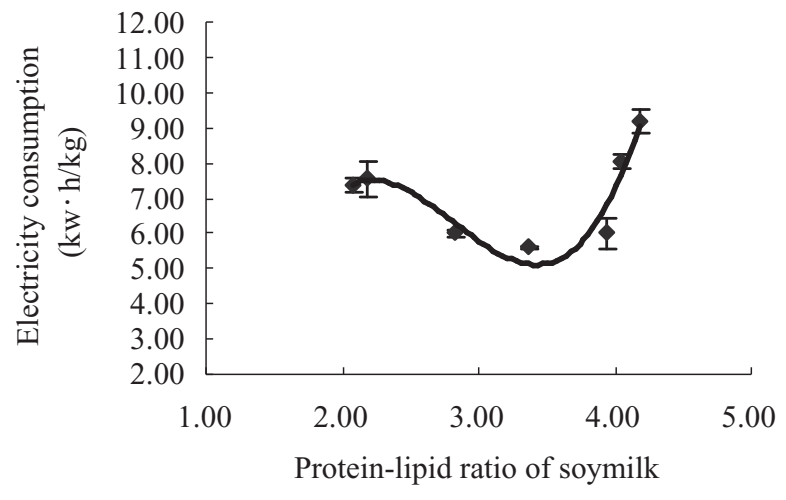

Fig. 8. Effects of protein-lipid ratio of soymilk adjusted by SPI and soybean oil on electricity consumption Vertical bars indicate standard errors. 


\section{Conclusions}

The effects of soybean cultivars, especially the concentrations of protein, lipid and protein-lipid ratio on protein-lipid film processing were investigated in the study. It was found that soybean cultivar significantly affected the yield and speed of film formation. The most suitable soybean cultivar among 7 cultivars for protein-lipid film production was Heisheng 101 (HS101). Protein-lipid ratio, not protein concentration itself, was an important factor which affects the yield and speed of film formation. A soybean cultivar that has high protein content and about 3.0 of protein-lipid ratio may be suitable for protein-lipid film production.

Furthermore, the effects of protein, lipid and proteinlipid ratio adjusted by SPI and soybean oil were investigated and the above results were affirmed.

It can be concluded that protein and lipid concentrations and protein-lipid ratio affected the production of protein-lipid film in yield, formation rate, PIE, LIE, and energy consumption. From the results of PIE and LIE, the use efficiency of protein did not change much with the varying of protein content but it changed obviously for lipid content. That is to say, a relative higher protein concentration, suitable lipid concentration and protein-lipid ratio may be the key factors which decided the PIE and LIE and then affected the yield of protein-lipid film.

\section{References}

1. Alzagtat, A. \& Alli, I. (2002) Protein-lipid interactions in food systems: a review. Int. J. Food Sci. Nutr., 53, 249260.

2. American Association of Cereal Chemists (1983) Method 44-16. In Approved methods of the AACC, American Association of Cereal Chemists, St. Paul, MN.

3. Borgstrom, G. (1969) Principles of food science. CollierMacmillan Ltd., London, pp. 426.

4. China State Bureau of Technical Supervision, P. R. China (1985) National standard of the People's Republic of China, GB/T 5009.6-1985.

5. China State Bureau of Technical Supervision, P. R. China (1985) National standard of the People's Republic of China, GB/T 5511-1985.

6. Han, Z., Ishitani, T. \& Li, Z. (2005) Effects of different soymilk concentrations and depth on the formation of yuba. Trans. CSAE, 21, 179-181.

7. Li, L., Li, Z. \& Yin, L. (2003) Processing and utilization of soybean. China Chemical Industry Press, Beijing, 210 212.

8. Liu, K. (1997) Soybeans: chemistry, technology, and utilization. Chapman and Hall Press, London, 137-289.

9. Ou, J., Wang, X. \& Jin, Q. (2005) Effects of soy ingredients on properties of dried bean milk cream in tight rolls. China Oils Fats, 30, 37-40.

10. Wu, L. \& Bates, R. (1972) Soy protein-lipid films. 1. Studies on the film formation phenomenon. J. Food Sci,. 37, 36-39.

11. Wu, L. \& Bates, R. (1972) Soy protein-lipid film. 2. Optimization of formation. J. Food Sci., 37, 40-44.

12. Wu, L. \& Bates, R. (1973) Influence of ingredients upon edible protein-lipid film characteristics. J. Food Sci., $\mathbf{3 8}$, 783-787.

13. Zhang, X. (1994) The muffled structure of protein and fats in yuba. J. Guangxi Norm. Univ., 12, 50-53. 